in vivo $35: 663-670(2021)$

doi:10.21873/invivo.12306

\title{
Quality of Life of Patients With Cancer During the COVID-19 Pandemic
}

\author{
KIM-ARTHUR BAFFERT, TIFFANY DARBAS, VALERIE LEBRUN-LY, JULIA PESTRE-MUNIER, \\ CLEMENTINE PEYRAMAURE, CLEMENTINE DESCOURS, MELANIE MONDOLY, SIMON LATROUITE, \\ ELISA BIGNON, SAMANTHA NICOULEAU, SOPHIE GEYL, SOPHIE LEOBON and ELISE DELUCHE
}

Department of Medical Oncology, University Hospital, Limoges, France

\begin{abstract}
Background: The COVID-19 pandemic has changed the organisation of medical care. Patients and Methods: This is the first prospective observational study on patient-reported outcomes, quality of life (HRQOL) and satisfaction in patients with cancer with their care management in a day hospital during the period of May-June 2020. The Generalised Anxiety Disorder Screener and 12Item Short-Form Health Survey were used. Results: The survey was completed by 189 of 267 patients. They were generally aged 61 to 70 years and women and presented with lung, breast, or colorectal cancer. Patients had low anxiety scores (mean: 3.2 \pm 4.5 ), with only $11.1 \%$ showing anxiety. Risk factors of anxiety included female gender $(p=0.03)$ and lifestyle (residence, family environment) $(p=0.01)$. The patient's physical health was stable, whereas mental health had deteriorated $(p<0.0001)$. Risk factors of altered HRQOL included age and lifestyle. Patients greatly appreciated all the facilities of the day hospital and its organisation. Conclusion: This study shows a preserved HRQOL and low anxiety of patients with cancer during the COVID-19 pandemic.
\end{abstract}

In France, the COVID-19 pandemic has changed the organisation of care since the beginning of March 2020, and various organisations have established specific recommendations for the management of patients undergoing medical oncology care. Patients have been identified as being vulnerable to COVID-19 because of their pathology

This article is freely accessible online.

Correspondence to: Elise Deluche, Medical Oncology, Limoges University Hospital, 2 avenue Martin Luther King, 87042 Limoges Cedex, France. Tel.: +33 555056100, Fax: +33 555056319, e-mail: elise.deluche@chu-limoges.fr

Key Words: Quality of life, patient-reported outcomes, anxiety, cancer, COVID-19. and treatment (1-3). They appear to be at greater risk of developing a severe form of coronavirus infection, particularly if they received chemotherapy in the months prior to the pandemic (1-3). For this reason, it has been recommended that the management of patients should be modified, including reducing hospital stays and initiating oral chemotherapy or targeted therapy when possible (4). This change in practice has required institutions to reorganise and develop structures for monitoring patients under treatment, which are essential for managing oral therapies at home and addressing specific side-effects. However, some patients had to undergo their treatment in hospital and their management was adapted according to the local level of infection. Thus, chemotherapy treatments continued in areas with minimal virus infection rates, with changes in patient management $(4,5)$. While many prior reports have been published on the management of patients, only a few have focused on the quality of life of patients, with or without cancer, during the pandemic $(6,7)$. Nevertheless, healthrelated quality of life (HRQOL) has become an important health outcome in cancer care and should be considered (8, 9). In addition to the disease and treatments, which have potential impacts on patient HRQOL $(10,11)$, we believe that the current context has affected quality of life in different ways depending on the intensity of circulation of the virus during COVID-19 pandemic.

The main objective of this study was to evaluate anxiety and HRQOL in patients who were treated in the day hospital of a Medical Oncology Department. The secondary objectives were tumour characteristics, patient assessment, their management, and non-psychological consequences.

\section{Patients and Methods}

Study design. In this cross-sectional study, patients managed in a day hospital of the Medical Oncology Department at Limoges Dupuytren Hospital were consecutively included over 4 weeks to minimise bias from the beginning of May 2020 to the beginning of June 2020 (after the first lockdown). 


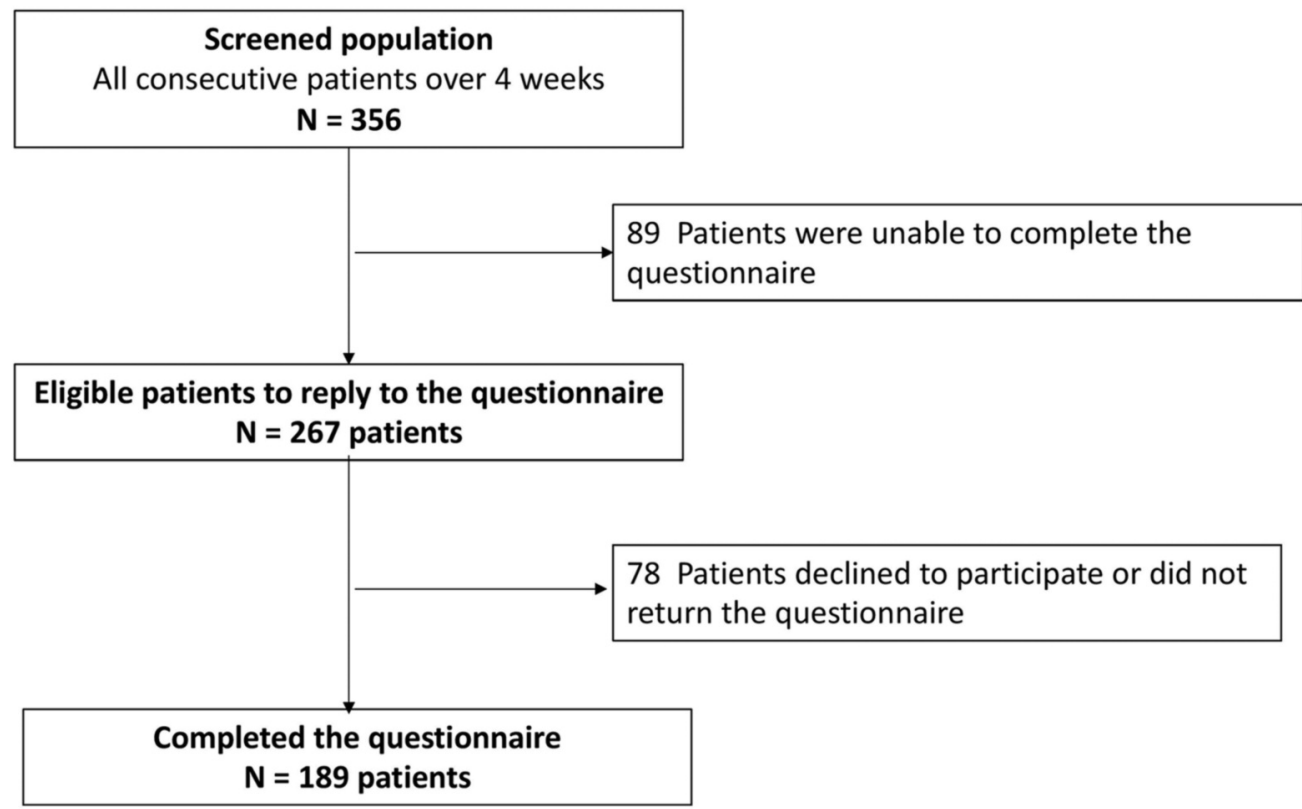

Figure 1. Flow-chart of study participants.

Participants. Anonymous paper questionnaires were distributed to patients to determine whether their cancer was metastatic, whether they were under chemotherapy/targeted therapy/immunotherapy. Patients were eligible if they were (i) diagnosed with a malignant tumour, (ii) aged more than 18 years (iii), able to read French, and (iv) had a performance status $<2$. Patients with combined oral and intravenous treatments or in clinical trials were also able to participate. The exclusion criteria were patients under hormone therapy or treated in an oral therapy centre and those unable to complete the questionnaire (physical or mental incapacity).

Reorganisation of the day hospital. During the COVID-19 epidemic, in accordance with the recommendations, the day hospital circuit was modified to avoid staying in the waiting room. Patients waited directly in rooms, with a maximum of two patients per room, at safe distances. On the day before each visit to the day hospital, patients were called to check for symptoms related to COVID-19. Limoges Dupuytren Hospital is located close to the countryside in a rural area. Many of our patients live outside of urban regions.

Assessments. An anonymous questionnaire with a letter explaining the background of the survey was provided to 267 eligible patients between May 2020 and June 2020. The questionnaire was divided into five parts and questions were mainly formulated with multiple choice answers: Sociodemographic and medical information, medical management during the COVID-19 pandemic, satisfaction with care management, quality of life, and anxiety. Only a few items required free text answers, such as date of cancer diagnosis. The results of all answers were recorded.

Objectives. One of our primary objectives was to evaluate anxiety; we used the Generalised Anxiety Disorder Screener (GAD-7) with total score ranging from 0 to 21 (12). GAD-7 scores $\geq 10$ and 15 suggest moderate and severe anxiety levels, respectively (13). Patients were evaluated at the end of lockdown and since the GAD7 score only evaluates anxiety in the previous two weeks, this is why we did not evaluate the impact of COVID-19 during lockdown. Quality of life was also evaluated using the 12-Item Short-Form Health Survey (SF-12) scale score $(14,15)$ before and after lockdown. This survey is composed of eight subscales (physical functioning, role physical, bodily pain, general health, vitality, social functioning, role emotional, and mental health) and two summary scales (Physical Composite Summary, PCS; Mental Composite Summary, MCS). The possible range of each domain score was 0100. A high score indicated better HRQOL.

The secondary objectives were to assess patient characteristics, to describe their management during the CODIV19 pandemic, and to assess the non-psychological consequences on quality of life, and to evaluate satisfaction with care management. Clinical data were reported by patients anonymously in the questionnaires. Patient satisfaction with the day hospital was rated on a numerical scale from 1 (not at all satisfied) to 10 (extremely satisfied).

Ethical approval. Regarding the anonymous survey, the Ethical Committee of the University Hospital of Limoges did not ask for a submission because the data collection was anonymised. Nevertheless, all participants were informed that this survey was mandated by the University Hospital of Limoges, concerned perceived SF-12, GAD-7 and health status, and they gave their verbal consent as recommended. Moreover, all patients at the beginning of their care accepted the use of their data by signing a consent form (Regional Solid Tumour dataBase validated on 04/28/2016- No. 200-2016-14).

Statistical analyses. All data were collected and analysed using STATVIEW software (SAS Institute Inc., Cary, NC, USA). 
Quantitative data are shown as the median \pm standard deviation (SD) and qualitative results as number with percentage. Nominal variables were compared between groups using the chi-square or Fisher's exact tests, as appropriate. Means were compared using the parametric Mann-Whitney $U$-test for continuous variables and the Wilcoxon signed-rank test for paired tests. A Spearman ranking correlation of the variables GAD-7, PCS, and MCS was performed. There was no predefined number of patient enrollments because all patients under management were considered.

\section{Results}

Study recruitment. Over the study period of 4 weeks, 356 patients were treated in the day hospital. Among them, 89 patients $(25 \%)$ were not eligible for the study (unable to read French or performance status $\geq 2$, or reason not reported). A total of 267 patients were included. Of these, 189 patients (70.7\%) returned the completed questionnaire. The reason for non-participation was not identified (Figure 1).

Sociodemographic and medical information. Patient characteristics are summarised in Table I. The group was generally aged between 61 and 70 years, and most of the patients were women. The localisation of cancer and the percentage of answers per cancer type are reported in Figure 2. Most patients had non-metastatic disease (79\%). Lung, breast, and colorectal cancer were the most common. Most responders had been diagnosed with their cancer within the previous 2 years (55\%). Patients mainly (62\%) lived near the hospital $(<50 \mathrm{~km})$. Their way of life was not affected during COVID-19 and only one case had a family reunification. Before COVID-19, most patients were retired (62\%) and only $22 \%$ were economically/professionally active. Professional lifestyle was affected in 10/37 patients regarding activity with disability. It was possible to compare respondents and nonrespondents by age and sex, and there were no differences between these two groups (data not shown).

Anxiety assessed by GAD-7. Patients had low anxiety scores (3.2 \pm 4.5$)$ after lockdown. A total of 21 patients $(11.1 \%)$ had anxiety with a GAD-7 score $>10$ and six (3.1\%) had high anxiety (GAD7 $\geq 15$ ). GAD-7 score was higher in female patients $(p=0.03)$ and in those who lived in a city apartment $(p=0.01)$ (Table II).

Quality of life evaluated using the SF-12 scale score. Before COVID-19, the mean PCS score was 48.5 and mean MCS score was 42.6. The PCS and MCS were better in patients aged $>60$ years $(p<0.04$ and $p=0.01$ respectively) (Table II). PCS was also better in patients who lived in a city apartment ( $p=0.0008)$, whereas MCS was better in patients who lived in individual houses $(p=0.01)$. A high MCS score was found in patients with children $(p=0.002)$ and with activity $(p=0.03)$.
Table I. Tumour and patient characteristics $(N=189)$.

\begin{tabular}{|c|c|c|c|}
\hline Characteristic & \multicolumn{2}{|l|}{ Subgroup } & $\mathrm{N},(\%)$ \\
\hline \multirow[t]{9}{*}{ Age at diagnosis } & \multicolumn{2}{|c|}{$<30$ Years } & $2(1)$ \\
\hline & \multicolumn{2}{|c|}{ 31-40 Years } & $6(3)$ \\
\hline & \multicolumn{2}{|c|}{ 41-50 Years } & $29(15)$ \\
\hline & \multicolumn{2}{|c|}{ 51-60 Years } & $48(25)$ \\
\hline & \multicolumn{2}{|c|}{ 61-70 Years } & $59(31)$ \\
\hline & \multicolumn{2}{|c|}{ 71-80 Years } & $37(20)$ \\
\hline & \multicolumn{2}{|c|}{ 81-90 Years } & $4(2)$ \\
\hline & \multicolumn{2}{|c|}{ >90 Years } & $1(1)$ \\
\hline & \multicolumn{2}{|l|}{ NA } & $3(2)$ \\
\hline \multirow[t]{3}{*}{ Gender } & \multicolumn{2}{|l|}{ Female } & $113(60)$ \\
\hline & \multicolumn{2}{|l|}{ Male } & $64(34)$ \\
\hline & \multicolumn{2}{|l|}{ NA } & $12(6)$ \\
\hline \multirow{4}{*}{$\begin{array}{l}\text { Distance from } \\
\text { hospital }\end{array}$} & \multicolumn{2}{|l|}{$<20 \mathrm{~km}$} & $62(33)$ \\
\hline & \multicolumn{2}{|l|}{$21-50 \mathrm{~km}$} & $56(29)$ \\
\hline & $51-100 \mathrm{kn}$ & & $43(23)$ \\
\hline & $>100 \mathrm{~km}$ & & $28(15)$ \\
\hline Date of cancer & 2020 & & $48(26)$ \\
\hline diagnosis & 2019 & & $54(29)$ \\
\hline & 2018 & & $19(10)$ \\
\hline & 2017 & & $19(10)$ \\
\hline & 2016 & & $10(5)$ \\
\hline & 2015 & & $0(0)$ \\
\hline & 2014 & & $6(3)$ \\
\hline & 2013 & & $2(1)$ \\
\hline & 2012 & & $4(2)$ \\
\hline & 2011 & & $2(1)$ \\
\hline & 2010 & & $2(1)$ \\
\hline & $<2010$ & & $11(6)$ \\
\hline & NA & & $12(6)$ \\
\hline Route of treatment & i.v. & & $169(89)$ \\
\hline administration* & Oral & & $2(1)$ \\
\hline & s.c. & & $3(2)$ \\
\hline & Other & & $3(2)$ \\
\hline & NA & & $13(7)$ \\
\hline Lifestyle during & Apartmen & & $31(16)$ \\
\hline COVID-19 & Individual & house & $153(82)$ \\
\hline pandemic & Retiremen & home & $0(0)$ \\
\hline & Other & & $2(1)$ \\
\hline & NA & & $3(1)$ \\
\hline & Alone & & $47(25)$ \\
\hline & In a coupl & & $141(75)$ \\
\hline & Children: & $\geq 18$ Years & $15(8)$ \\
\hline & & $<18$ Years & $22(12)$ \\
\hline & Pet: & Yes & $95(50.5)$ \\
\hline & & No & $93(49.5)$ \\
\hline Change of lifestyle & Yes & & $1(0.5)$ \\
\hline since COVID-19 & No & & $187(99.5)$ \\
\hline Professional situation & Active & & $39(20)$ \\
\hline before COVID-19 & Active, ch & anged since COVID-19: & \\
\hline & & Yes & $10(27)$ \\
\hline & & No & $0(0)$ \\
\hline & & NA & $29(73)$ \\
\hline & Retired & & $106(57)$ \\
\hline & Unemploy & & $11(6)$ \\
\hline & Disability & & $15(8)$ \\
\hline & In training & & $1(0.5)$ \\
\hline & Other & & $16(8)$ \\
\hline & NA & & $1(0.5)$ \\
\hline
\end{tabular}

NA: Not reported by the patient. *One patient reported two treatments. 
in vivo $35: 663-670(2021)$

Table II. Self-reported anxiety (GAD7) after lockdown and health-related quality of life (SF-12) scale scores before and after lockdown.

\begin{tabular}{|c|c|c|c|c|c|c|c|c|c|c|}
\hline & \multicolumn{2}{|c|}{ GAD-7 } & \multicolumn{4}{|c|}{$\mathrm{MCS}$, mean $\pm \mathrm{SD}$} & \multicolumn{4}{|c|}{$\mathrm{PCS}$, mean $\pm \mathrm{SD}$} \\
\hline & $\mathrm{Mean} \pm \mathrm{SD}$ & $p$-Value & Before & $p$-Value & After & $p$-Value & Before & $p$-Value & After & $p$-Value \\
\hline Total & $3.2 \pm 4.5$ & & $42.6 \pm 17.5$ & & $36.1 \pm 14.3$ & $<0.001$ & $48.5 \pm 10.7$ & & $46.7(12.4)$ & 0.9 \\
\hline \multicolumn{11}{|l|}{ Age at diagnosis } \\
\hline$<60$ Years & $3.3 \pm 0.5$ & 0.83 & $47.0 \pm 1.7$ & 0.005 & $20.9 \pm 1.4$ & 0.01 & $23.6 \pm 2.3$ & 0.04 & $31.1 \pm 2.09$ & 0.009 \\
\hline >60 Years & $3.1 \pm 0.4$ & & $39.4 \pm 1.6$ & & $27.2 \pm 1.4$ & & $29.5 \pm 2.2$ & & $23.6 \pm 2.1$ & \\
\hline \multicolumn{11}{|l|}{ Gender } \\
\hline Male & $2.60 \pm 0.5$ & 0.03 & $42.8 \pm 2.0$ & 0.8 & $26.4 \pm 1.2$ & 0.49 & $26.4 \pm 2.3$ & 0.2 & $24.7 \pm 2.5$ & 0.2 \\
\hline Female & $3.7 \pm 0.4$ & & $43.2 \pm 1.6$ & & $24.1 \pm 2.0$ & & $28.8 \pm 2.1$ & & $29.1 \pm 1.9$ & \\
\hline \multicolumn{11}{|l|}{ Distance from hospital } \\
\hline$<50 \mathrm{~km}$ & $3.1 \pm 0.5$ & 0.91 & $42.8 \pm 2.2$ & 0.8 & $25.5 \pm 1.4$ & 0.19 & $27.0 \pm 3.1$ & 0.8 & $26.9 \pm 2.5$ & 0.6 \\
\hline$>50 \mathrm{~km}$ & $3.3 \pm 0.4$ & & $42.8 \pm 1.5$ & & $22.3 \pm 1.5$ & & $27.4 \pm 1.8$ & & $27.4 \pm 1.9$ & \\
\hline \multicolumn{11}{|l|}{ Lifestyle } \\
\hline Apartment & $4.6 \pm 0.9$ & 0.01 & $36.2 \pm 3.1$ & 0.01 & $26.7 \pm 2.9$ & 0.15 & $37.4 \pm 3.3$ & 0.0008 & $32.8 \pm 3.7$ & 0.06 \\
\hline Individual house & $2.8 \pm 0.3$ & & $44.0 \pm 1.3$ & & $23.8 \pm 1.1$ & & $24.4 \pm 1.7$ & & $25.5 \pm 1.6$ & \\
\hline Alone & $3.13 \pm 0.5$ & 0.74 & $40.1 \pm 1.4$ & 0.2 & $23.9 \pm 1.8$ & 0.75 & $28.3 \pm 1.9$ & 0.5 & $30.7 \pm 2.9$ & 0.08 \\
\hline Couple & $3.23 \pm 0.3$ & & $43.6 \pm 2.2$ & & $24.7 \pm 1.2$ & & $28.3 \pm 2.7$ & & $24.6 \pm 1.7$ & \\
\hline With & $3.3 \pm 0.5$ & 0.09 & $49.8 \pm 1.9$ & 0.002 & $23.2 \pm 2$ & 0.5 & $22.1 \pm 3.0$ & 0.1 & $26.0 \pm 3.0$ & 0.9 \\
\hline Without children & $2.71 \pm 0.3$ & & $40.5 \pm 1.4$ & & $24.7 \pm 1.2$ & & $28.2 \pm 1.8$ & & $26.7 \pm 1.7$ & \\
\hline \multicolumn{11}{|l|}{ Pet: } \\
\hline Yes & $4.36 \pm 0.4$ & 0.69 & $43.7 \pm 1.5$ & 0.4 & $25.0 \pm 1.5$ & 0.5 & $26.4 \pm 2.3$ & 0.8 & $26.3 \pm 2.2$ & 0.6 \\
\hline No & $4.61 \pm 0.4$ & & $41.8 \pm 1.7$ & & $23.7 \pm 1.4$ & & $27.0 \pm 2.3$ & & $27.2 \pm 2.0$ & \\
\hline \multicolumn{11}{|l|}{ Professional situation } \\
\hline Active & $4.3 \pm 0.6$ & 0.65 & $45.8 \pm 2.6$ & 0.03 & $20.9 \pm 2.3$ & 0.04 & $22.8 \pm 3.4$ & 0.07 & $30.0 \pm 2.9$ & 0.06 \\
\hline Retired/unemployed & $4.6 \pm 0.4$ & & $40.6 \pm 1.4$ & & $26.05 \pm 1.1$ & & $27.9 \pm 1.9$ & & $24.8 \pm 1.8$ & \\
\hline
\end{tabular}

MCS: Mental Composite Summary; PCS: Physical Composite Summary; SD: standard deviation.

At the end of the 4-week study period, the patient's physical health (PCS mean score) was stable (46.7; $p=0.866$ ), whereas their mental health (MCS mean score) decreased $(36.1 ; p<0.0001)$ (Table II). The PCS was better in patients aged $<60$ years (31.1 2.09 vs. 23.6 \pm 2.1 ; $p<0.009)$, whereas the MCS remained stable and better in patients aged $>60$ years $(p=0.01)$. MCS was better in retired patients $(p=0.04)$ (Table II). There was no correlation between GAD-7 and PCS or MCS $(p>0.05)$.

Medical management during the COVID-19 pandemic. Table III presents the results of medical management. During the 4-week study period, only $8 \%$ of our patients presented with signs suspicious of COVID-19 and were tested. None of the patients tested positive. Before presenting to the hospital, the majority of patients were called by phone to check for symptoms $(63 \%)$. For other patients, we did not cancel examinations required for their treatment and consulted the emergency unit if necessary (93\%). In hospital, the majority of cancer-related analyses were physically maintained in $67 \%$ of cases compared to $28 \%$ if they were not associated with cancer, and 6 to $8 \%$ were maintained by teleconsultation. Only $6 \%$ of appointments were postponed without a new date. The very large majority of patients positively appreciated the medical changes made (91\%).
During the epidemic, only two patients died of COVID-19 out of the 600 patients treated orally and venously at the day hospital and at our oral therapy center (16).

Patient satisfaction with care management. The reorganisation of day hospital care changed patient habits in $31 \%$ of cases. Activities during treatment were mainly conversation with day hospital staff $(67 \%)$ and using the phone $(63 \%)$ and television $(52 \%)$. A total of $16 \%$ of patients were used to talking with an accompanying person and were unable to do so due to restrictions (Table IV). Patients greatly appreciated the facilities of the day hospital and its organisation, with ratings ranging from $8.1 \pm 1.8$ to $9.2 \pm 1.0$. The most criticised point was the waiting time, which increased but was considered acceptable (score $8.1 \pm 1.8$ ).

\section{Discussion}

As far as we are aware, our study evaluated for the first time the anxiety status and quality of life of patients managed in a day hospital unit of medical oncology in a COVID-19-low area after lockdown. In a real-life situation, we provide a picture of anxiety and quality of life post-containment. Overall, anxiety levels remained low in post-lockdown and the proportion of patients with high anxiety was similar to 
Table III. Medical management during COVID-19 pandemic.

\begin{tabular}{|c|c|c|}
\hline & & $\mathrm{N},(\%)$ \\
\hline \multirow[t]{7}{*}{ Test for COVID-19 } & No & $159(84)$ \\
\hline & Yes, nasal test & $11(6)$ \\
\hline & Yes, scanner test & $3(1.5)$ \\
\hline & Yes, other & $1(0.5)$ \\
\hline & NA & $15(8)$ \\
\hline & Positive result & $0(0)$ \\
\hline & Negative result & $15(100)$ \\
\hline \multirow{3}{*}{$\begin{array}{l}\text { Answering calls } \\
\text { before going to the } \\
\text { day hospital }\end{array}$} & Yes & $120(63)$ \\
\hline & No & $64(34)$ \\
\hline & NA & $5(3)$ \\
\hline \multirow{7}{*}{$\begin{array}{l}\text { Because of the risk of } \\
\text { infection by the virus, } \\
\text { have you self-referred } \\
\text { to consult or go to the } \\
\text { Emergency Unit for } \\
\text { symptoms related to } \\
\text { cancer or treatment? }\end{array}$} & Yes & $5(3)$ \\
\hline & No & $176(93)$ \\
\hline & NA & $8(4)$ \\
\hline & & \\
\hline & & \\
\hline & & \\
\hline & & \\
\hline \multirow{6}{*}{$\begin{array}{l}\text { Have any tests related } \\
\text { to your cancer been } \\
\text { scheduled? }\end{array}$} & Cancelled & $13(6)$ \\
\hline & Scheduled & $22(11)$ \\
\hline & Maintained at the centre & $136(67)$ \\
\hline & Maintained by teleconsultation & $17(8)$ \\
\hline & Not concerned by the issue & $7(4)$ \\
\hline & $\mathrm{Na}$ & $7(4)$ \\
\hline \multirow{6}{*}{$\begin{array}{l}\text { Have any tests NOT } \\
\text { related to your cancer } \\
\text { been scheduled? }\end{array}$} & Cancelled & $11(6)$ \\
\hline & Scheduled & $21(11)$ \\
\hline & Maintained at the centre & $54(28)$ \\
\hline & Maintained by teleconsultation & $5(2)$ \\
\hline & Not concerned by the issue & $68(35)$ \\
\hline & NA & $35(18)$ \\
\hline \multirow[t]{6}{*}{ Impact of the changes } & Very negative & $3(2)$ \\
\hline & Negative & $4(3)$ \\
\hline & Rather negative & $5(4)$ \\
\hline & Rather positive & $12(10)$ \\
\hline & Positive & $31(24)$ \\
\hline & Very positive & $72(57)$ \\
\hline
\end{tabular}

NA: Not reported by the patient.

that described in adults with cancer $(17,18)$. Risk factors for anxiety post-lockdown include female gender and living in an apartment. Zeynalova et al. also reported that female gender was a risk factor for anxiety in patients with cancer (odds ratio $=1.8,95 \%$ confidence intervaI $=1.5-2.2 ; p<0.001$ ) (19). In our study, we showed that the level of anxiety remained low in a region where the rate of infection was limited and where patients had a preserved quality of life (possibility by having a nice home in a rural area) and where the organisation of care was globally maintained.

PCS and MCS scores before the 4-week study period were relatively similar to previous reports $(20,21)$. The impact on PCS, composed of four scales assessing physical function, role limitations caused by physical problems, bodily pain, and general health, did not differ significantly from published data $(15,22,23)$. MCS data, including limitations caused by
Table IV. Satisfaction with care in the Oncology Department of the day hospital.

\begin{tabular}{|c|c|c|}
\hline & & $\mathrm{N},(\%)$ \\
\hline \multirow{8}{*}{$\begin{array}{l}\text { During your day } \\
\text { hospital sessions, } \\
\text { what did you do } \\
\text { during your waiting } \\
\text { time? } \\
\text { prior to COVID19? }\end{array}$} & Book reading & $93(50)$ \\
\hline & Conversation with other patients & $86(45)$ \\
\hline & $\begin{array}{l}\text { Conversation with day } \\
\text { hospital staff }\end{array}$ & $126(67)$ \\
\hline & Using phone & $119(63)$ \\
\hline & Using television & $99(52)$ \\
\hline & Nothing special & $32(17)$ \\
\hline & Listening to music & $29(15)$ \\
\hline & $\begin{array}{l}\text { Discussion with the } \\
\text { accompanying person prior } \\
\text { to COVID-19 }\end{array}$ & $31(16)$ \\
\hline \multirow{4}{*}{$\begin{array}{l}\text { Change since } \\
\text { COVID-19? }\end{array}$} & Yes & $58(31)$ \\
\hline & No & $116(61)$ \\
\hline & NA & $15(8)$ \\
\hline & & Mean \pm SD \\
\hline \multirow{6}{*}{$\begin{array}{l}\text { Level of satisfaction } \\
\text { (between } 1 \text { to } 10 \text { ) }\end{array}$} & Quality of reception & $9.2 \pm 1.0$ \\
\hline & $\begin{array}{l}\text { Availability of nursing staff } \\
\text { for patients }\end{array}$ & $9.2 \pm 1.0$ \\
\hline & $\begin{array}{l}\text { Organisation of the patient's } \\
\text { journey }\end{array}$ & $9.1 \pm 1.1$ \\
\hline & Preservation of privacy & $9.0 \pm 1.1$ \\
\hline & Waiting time & $8.1 \pm 1.8$ \\
\hline & Organisation of the treatment room & n $8.8 \pm 1.4$ \\
\hline
\end{tabular}

NA: Not reported by the patient; SD standard deviation.

emotional problems, vitality, social functioning, and mental health were affected post-lockdown. The MCS was not related to anxiety level. It is interesting to note that the post-lockdown MCS data did not return to pre-lockdown scores, probably due to the current atmosphere $(15,22,23)$. The score 'age' is a risk factor for PCS and MCS. Age is known to be inversely associated with PCS and MCS. Individuals aged $<60$ years seemed to have the lowest physical state at the beginning of treatment and the best psychological state after treatment, but this was reversed post-lockdown. These data should be considered with caution as we did not take into account the treatment for these patients, which might have explained some variations. Deconfinement seemed to benefit more individuals over 60 years old and fewer who were about 60 years old who, we imagine, may be confronted with problems related to their return to activity. The MCS was better in retired patients than in professionally active patients. As our population was over 60 years of age, social problems related to professional situations were limited. Various factors in this regard had no impact on the quality of life involving factors such as sex, having animals and children, being in a relationship, or living at a distance from the hospital.

The study was also designed to assess hospital-based management during the COVID-19 period. These data are interesting because they reveal data in a region that was only 


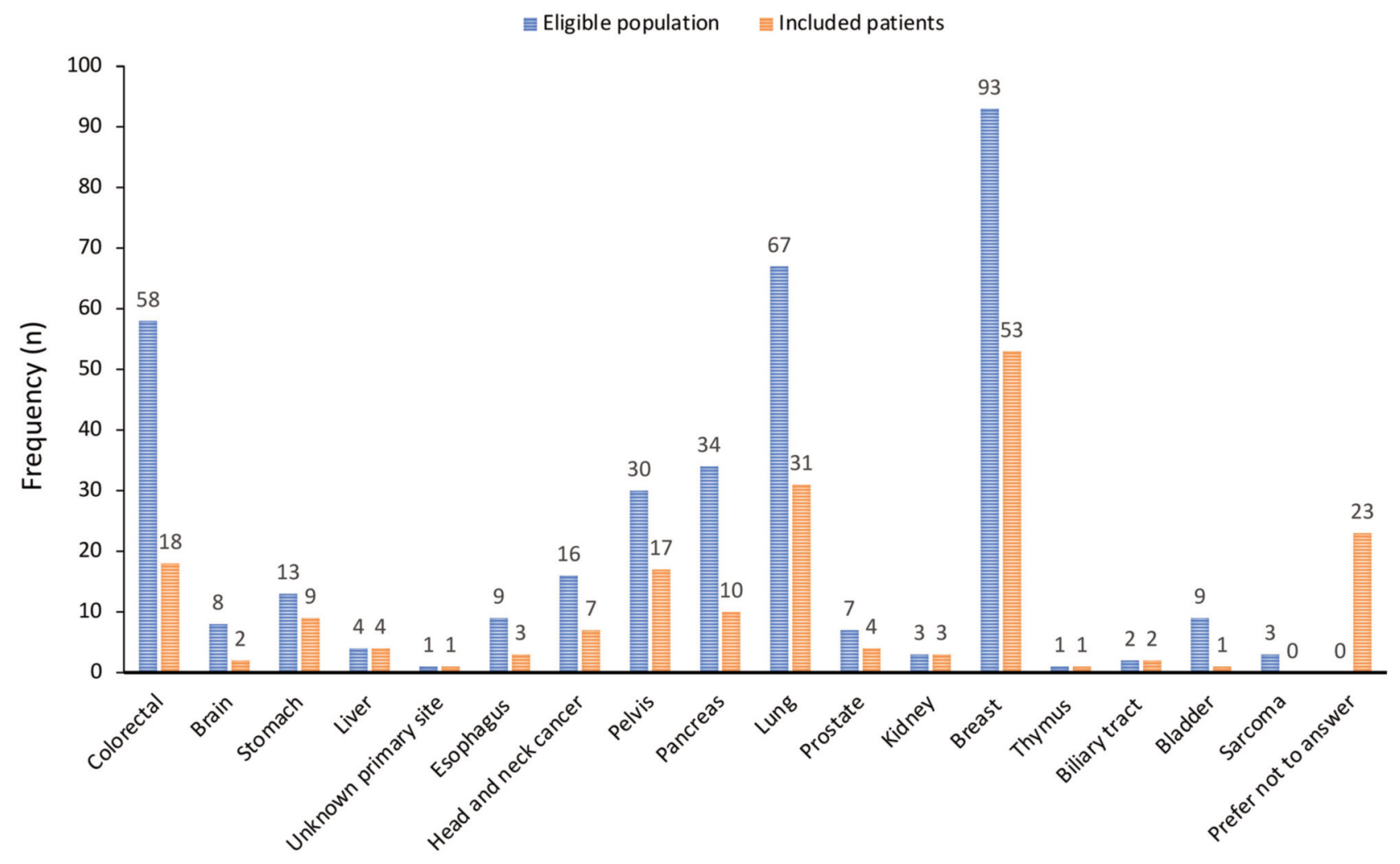

Figure 2. Type of cancer in eligible populations and in patients completing the questionnaire.

slightly affected by COVID-19. Not all regions in France have been similarly affected by the COVID-19 pandemic, even if it is currently the primary health concern worldwide. Europe constituted one of the epicentres of the pandemic, especially in Italy, with the number of deaths there surpassing those in China. In France, all 13 regions were not similarly affected according to the French Public Health Department. Most regions, including our own, had a low forecast of expected disease (24), which was subsequently confirmed after lockdown. These data have allowed us to maintain some activity in the Oncology Department. Due to the COVID-19 crisis, healthcare professionals were challenged by profoundly re-organising healthcare systems not only to handle the COVID-19 pandemic effectively but also to do so without losing sight of patient care (25). It was important for health professionals to consider that mortality from cancer remained significant, and not to be entirely distracted by COVID-19. We had a limited number of patients who refused treatment compared to what was reported by our Italian colleagues, who experienced a much more virulent epidemic. Only $3 \%$ of patients did not attend appointments because of anxiety about COVID-19 (7); only $7.9 \%$ of patients presented with symptoms suspicious of COVID-19, and none had positive results. Our study also raised the question of whether recommendations should be established uniformly within the same territory or regionally based on the density of circulating viruses. Otherwise, the risk is to undertreat patients, the impact of which we will only see in the near future, thanks to ongoing studies.

The strengths of our study are the number of responses obtained in a short period of time, the low rate of missing data and the representativeness of cancer types. The limitations of this work are related to the use of anonymous questionnaires. As consecutive patients were approached, the potential for selection bias was minimized. In addition, the studied population was compared to that of 2019, which confirmed the representativeness of this population. Since not all patients participated in the questionnaire, there was a risk of selecting the most motivated patients. This tendency has been noted previously in other studies $(26,27)$. However, we had a high participation rate and all types of cancer were represented, which limits selection bias. The high rate of non-metastatic cancer seems to be due to a lack of patient awareness or understanding of the issue, as it is most likely with retrospectively administered treatments that $40 \%$ of patients would be considered to have metastatic disease. It will be interesting to have a longitudinal follow-up of patients to capture the evolution of quality of life anxiety during COVID-19 and in the event of a new wave. 


\section{Conclusion}

This study shows that the anxiety rate in patients with cancer remained low post-lockdown in areas minimally affected by COVID-19, with a preserved quality of life. It also shows that the changes made in management were positively received by patients. These elements will be important in the event of new crises when it comes to reorganising local care practices.

\section{Conflicts of Interest}

None declared.

\section{Authors' Contributions}

$\mathrm{KAB}$ and ED drafted the work; participated in the conception and design of the work, and in the acquisition and interpretation of the data; approved the last version; and ensured the accuracy and integrity of any part of the work. KA, MM, SL, EB, SN, were involved in the distribution and implementation of the questionnaire. ED participated in the analysis and interpretation of the data, revised it critically, approved the last version, and ensured the accuracy and integrity of any part of the work. TD, VLL, JP, CP, CD, SG and SL participated in the conception and design of the work, revised it critically, approved the last version, and ensured the accuracy and integrity of any part of the work.

\section{Acknowledgements}

The Authors thank the students in Medical Oncology for their participation in this study. We thank Textcheck for their assistance with editing the language of the article.

\section{References}

1 Miyashita H, Mikami T, Chopra N, Yamada T, Chernyavsky S, Rizk D and Cruz C: Do Patients with Cancer Have a Poorer Prognosis of COVID-19? An Experience in New York City. Ann Oncol, 2020. PMID: 32330541. DOI: 10.1016/j.annonc. 2020.04 .006

2 Liang W, Guan W, Chen R, Wang W, Li J, Xu K, Li C, Ai Q, Lu W, Liang H, Li S and He J: Cancer patients in SARS-CoV-2 infection: a nationwide analysis in China. Lancet Oncol 21: 335337, 2020. PMID: 32066541. DOI: 10.1016/S1470-2045(20) 30096-6

$3 \mathrm{Wu} \mathrm{Z}$ and McGoogan JM: Characteristics of and important lessons from the Coronavirus disease 2019 (COVID-19) outbreak in China: Summary of a report of 72314 cases from the Chinese Center for Disease Control and Prevention. JAMA 323: 1239-1242, 2020. PMID: 32091533. DOI: 10.1001/jama. 2020.2648

4 Recommandations et COVID-19. Onco-Nouvelle-Aquitaine. Available at: https://onco-nouvelle-aquitaine.fr/recommandationsrelatives-a-la-prevention-et-a-la-prise-en-charge-du-covid-19chez-les-patients-a-risque-de-formes-severes/ [Last accessed June 17, 2020]

5 Grellety T, Ravaud A, Canivet A, Ganem G, Giraud P, Guimbaud R, Kaluzinski L, Krakowski I, Mayeur D, Lotz J-P and You B: Infection à SARS-CoV-2/COVID 19 et cancers solides: synthèse des recommandations à l'attention des professionnels de santé. Bull Cancer 107: 400-402, 2020. PMID: 32229048. DOI: 10.1016/j.bulcan.2020.03.001

6 Wang C, Pan R, Wan X, Tan Y, Xu L, Ho CS and Ho RC: Immediate psychological responses and associated factors during the initial stage of the 2019 Coronavirus disease (COVID-19) epidemic among the general population in China. Int J Environ Res Public Health 17, 2020. PMID: 32155789. DOI: 10.3390/ijerph17051729.

7 Vanni G, Materazzo M, Pellicciaro M, Ingallinella S, Rho M, Santori F, Cotesta M, Caspi J, Makarova A, Pistolese CA and Buonomo OC: Breast cancer and COVID-19: The effect of fear on patients' decision-making process. In Vivo 34: 1651-1659, 2020. PMID: 32503825. DOI: 10.21873/invivo.11957

8 Fiteni F, Ray IL, Ousmen A, Isambert N, Anota A and Bonnetain F: Health-related quality of life as an endpoint in oncology phase I trials: a systematic review. BMC Cancer 19: 361, 2019. PMID: 30991990. DOI: 10.1186/s12885-019-5579-3

9 Wedding U, Pientka L and Höffken K: Quality-of-life in elderly patients with cancer: a short review. Eur J Cancer 43: 22032210, 2007. PMID: 17662595. DOI: 10.1016/j.ejca.2007.06.001

10 Chau I, Fuchs CS, Ohtsu A, Barzi A, Liepa AM, Cui ZL, Hsu Y and Al-Batran S-E: Association of quality of life with disease characteristics and treatment outcomes in patients with advanced gastric cancer: Exploratory analysis of RAINBOW and REGARD phase III trials. Eur J Cancer 107: 115-123, 2019. DOI: 10.1016/j.ejca.2018.11.013

11 Hamer J, McDonald R, Zhang L, Verma S, Leahey A, Ecclestone C, Bedard G, Pulenzas N, Bhatia A, Chow R, DeAngelis C, Ellis J, Rakovitch E, Lee J and Chow E: Quality of life (QOL) and symptom burden (SB) in patients with breast cancer. Support Care Cancer 25: 409-419, 2017. DOI: 10.1007/s00520-0163417-6

12 Esser P, Hartung TJ, Friedrich M, Johansen C, Wittchen H-U, Faller H, Koch U, Härter M, Keller M, Schulz H, Wegscheider $\mathrm{K}$, Weis J and Mehnert A: The Generalized Anxiety Disorder Screener (GAD-7) and the anxiety module of the Hospital and Depression Scale (HADS-A) as screening tools for generalized anxiety disorder among cancer patients. Psychooncol 27: 15091516, 2018. PMID: 29473255. DOI: 10.1002/pon.4681

13 Andersen BL, DeRubeis RJ, Berman BS, Gruman J, Champion VL, Massie MJ, Holland JC, Partridge AH, Bak K, Somerfield MR and Rowland JH: Screening, assessment, and care of anxiety and depressive symptoms in adults with cancer: An American Society of Clinical Oncology guideline adaptation. J Clin Oncol 32: 1605-1619, 2014. PMID: 24733793. DOI: 10.1200/JOP. 2014.002311

14 Roydhouse JK, Gutman R, Keating NL, Mor V and Wilson IB: Proxy and patient reports of health-related quality of life in a national cancer survey. Health Qual Life Outcomes 16: 6, 2018. PMID: 29304818. DOI: 10.1186/s12955-017-0823-5

15 Kenzik K, Ganz PA, Martin M, Petersen L, Hays RD, Arora N and Pisu M: How much do cancer-related symptoms contribute to health-related quality of life in lung and colorectal cancer patients? A report from the Cancer Care Outcomes Research and Surveillance (CanCORS) Consortium. Cancer 121: 2831-2839, 2015. PMID: 25891437. DOI: 10.1002/cncr.29415

16 Deluche E, Darbas T, Bourcier K, Montangon L, Bayard G, Caille E, Querrioux J, Suchaud C, Zabaleta S, Chaput S, Le 
Brun-Ly V, Pestre J, Venat L, Thuillier F, Nevado E, Maillan G, Jost J, Leobon S, Tubiana-Mathieu $\mathrm{N}$ and Lavau-Denes S: Prospective evaluation of an anti-cancer drugs management programme in a dedicated oral therapy center (DICTO programme). Med Oncol 37: 69, 2020. PMID: 32712771. DOI: 10.1007/s12032-020-01393-7

17 Sarkar S, Sautier L, Schilling G, Bokemeyer C, Koch U and Mehnert A: Anxiety and fear of cancer recurrence and its association with supportive care needs and health-care service utilization in cancer patients. J Cancer Surviv 9: 567-575, 2015. PMID: 25676473. DOI: 10.1007/s11764-015-0434-2

18 Plummer F, Manea L, Trepel D and McMillan D: Screening for anxiety disorders with the GAD-7 and GAD-2: a systematic review and diagnostic metaanalysis. Gen Hosp Psychiatry 39: 24-31, 2016. PMID: 26719105. DOI: 10.1016/j.genhosppsych. 2015.11.005

19 Zeynalova N, Schimpf S, Setter C, Yahiaoui-Doktor M, Zeynalova S, Lordick F, Loeffler M and Hinz A: The association between an anxiety disorder and cancer in medical history. J Affect Disord 246: 640-642, 2019. PMID: 30611061. DOI: 10.1016/j.jad.2018.12.019

20 Wei JT, Dunn RL, Litwin MS, Sandler HM and Sanda MG: Development and validation of the expanded prostate cancer index composite (EPIC) for comprehensive assessment of health-related quality of life in men with prostate cancer. Urology 56: 899-905, 2000. PMID: 11113727. DOI: 10.1016/s0090-4295(00)00858-x

21 Bhandari NR, Kathe N, Hayes C and Payakachat N: Reliability and validity of SF-12v2 among adults with self-reported cancer. Res Social Adm Pharm 14: 1080-1084, 2018. PMID: 29366669. DOI: 10.1016/j.sapharm.2018.01.007

22 Husson O, Zebrack BJ, Block R, Embry L, Aguilar C, HayesLattin B and Cole S: Health-related quality of life in adolescent and young adult patients with cancer: A longitudinal study. JCO 35: 652-659, 2017. PMID: 28095151. DOI: 10.1200/JCO. 2016.69.7946
23 Hsueh-Wen C, Li-Yin C, Sheng-Miauh H, Chen-Jeng T and Chen-Jei T: Changes in symptom patterns and health-related quality of life of cancer patients before and after chemotherapy. J Tradit Chin Med 36: 326-331, 2016. PMID: 27468547. DOI: 10.1016/s0254-6272(16)30045-0

24 Massonnaud C, Roux J and Crépey P: COVID-19: Forecasting short term hospital needs in France. medrxiv, 2020. DOI: 10.1101/2020.03.16.20036939

25 van de Haar J, Hoes LR, Coles CE, Seamon K, Fröhling S, Jäger D, Valenza F, de Braud F, De Petris L, Bergh J, Ernberg I, Besse B, Barlesi F, Garralda E, Piris-Giménez A, Baumann M, Apolone G, Soria JC, Tabernero J, Caldas C and Voest EE: Caring for patients with cancer in the COVID-19 era. Nat Med 26: 665-671, 2020. PMID: 32405058. DOI: 10.1038/s41591020-0874-8

26 van Gelder MMHJ, Bretveld RW and Roeleveld N: Web-based questionnaires: the future in epidemiology? Am J Epidemiol 172: 1292-1298, 2010. PMID: 20880962. DOI: 10.1093/ aje/kwq291

27 Ebert JF, Huibers L, Christensen B and Christensen MB: Paperor web-based questionnaire invitations as a method for data collection: Cross-sectional comparative study of differences in response rate, completeness of data, and financial cost. J Med Internet Res 20: e24, 2018. PMID: 29362206. DOI: 10.2196/ jmir.8353
Received November 8, 2020

Revised November 22, 2020

Accepted November 25, 2020 